\title{
Factors Influencing Students' Selection of Different Types of Essay in Examination
}

\author{
Harwati Hashim, Melor Md. Yunus, Najihah Syazwani Mohamad Yusuf, \\ Nur Afifah Hasya Zanzuri, Marya Hasnah Ruslee, Siti Munirah Fakhruddin \\ Centre of Teaching and Learning Innovations, Faculty of Education, Universiti Kebangsaan Malaysia, Bangi, Malaysia \\ Email: melor@ukm.edu.my
}

How to cite this paper: Hashim, H., Yunus, M. Md., Yusuf, N. S. M., Zanzuri, N. A. H., Ruslee, M. H., \& Fakhruddin, S. M. (2018). Factors Influencing Students' Selection of Different Types of Essay in Examination. Creative Education, 9, 23342340.

https://doi.org/10.4236/ce.2018.914173

Received: August 16, 2018

Accepted: October 28, 2018

Published: October 31, 2018

Copyright $\odot 2018$ by authors and Scientific Research Publishing Inc. This work is licensed under the Creative Commons Attribution International License (CC BY 4.0).

http://creativecommons.org/licenses/by/4.0/

(c) (i) Open Access

\begin{abstract}
In English language learning, writing a good essay is a challenging activity as it requires synthesis of material that cannot be done in a very short time. Furthermore, students are required to support their argument with evidence, and this may involve memorizing some key events, or the names of places, etc. Before organising their ideas, knowledge of the subject matter is important as part of the preparation process. Therefore, students usually have difficulties in selecting type of essay in examination. Students spent more time choosing type of essay to be answered as they need to consider their knowledge or content when answering the question. Thus, this study was conducted to identify factors influencing students' selection for different type of essay. There are four types of essay included in the syllabus which is factual essay, narrative essay, descriptive essay, reflective essay and argumentative essay. Quantitative research design was employed in this study. A total of 70 upper secondary school students from different schools in Pahang, Malaysia were involved as respondents. Data were analysed and presented using frequencies and percentages. The findings showed that the factor that influences them the most in selecting the different type of essay question is their content knowledge. Meanwhile, choices of words (vocabulary) and confidence in their writing skills are the least. In conclusion, the findings showed that there is a need for students to be exposed with more content in writing.
\end{abstract}

\section{Keywords}

Factors, Types of Essay, English as a Second Language, ESL, Examination

\section{Introduction}

In English language learning, writing a good essay is a challenging activity as it requires synthesis of material that cannot be done in a very short time. Further- 
more, students are required to support their argument with evidence, and this may involve memorizing some key events, or the names of places, etc. Before organising their ideas, knowledge of the subject matter is important as part of the preparation process. Therefore, students usually have difficulties in selecting type of essay in examination. Students spent more time choosing type of essay to be answered as they need to consider their knowledge or content when answering the question.

Common issue among Malaysian high school students is that they tend to take too much time choosing type of essay that they can score well. In fact, some students also experience having to choose between 2 to 3 essays that they want. This study is significant as a reference for English teachers in understanding factors that influencing students' selection of type of essay question during examination and thus reflects their score for the essay question.

Thus, this study was conducted to identify factors influencing students' selection of different type of essay. There are five types of essay included in the syllabuses which are factual essay, narrative essay, descriptive essay, reflective essay and argumentative essay.

\section{Literature Review}

A huge number of international contacts communicate and deals using English language (Al-Khasawneh, 2010). Therefore, the existence of competent writers and speakers of English is of a great importance for today's world. According to (Tan \& Miller, 2008), writing is an intentional, social communication that involves literacy as well. Furthermore, it is taken as a means of social practices, through which patterns of participation, gender preferences, networks of support and collaboration, patterns of time use, space, tools, technology and resources are applied.

In addition, through the interaction of writing with reading and written language with other semiotic modes, the symbolic meanings of literacy, and the broader social goals take place. This is exactly what literacy serves in the lives of people and institutions. Zamel (1983) considered writing process as a non-linear, exploratory, and generative process whereby writers discover and reformulate their ideas.

Writing is one of the important means by which students actively transform the passive knowledge and information in their minds into their own language (Chow, 2007). However, writing has always been a difficult task for individuals especially for English as a Second Language (ESL) learners in Malaysia. ESL teachers in Malaysia confirm the problems in writing development, especially in conventions, and punctuation (Ghabool \& Kashef, 2012). Additionally, lack of English language proficiency has always become the main cause of difficulties that ESL learners have in their writing tasks. Extensive studies have been done to investigate the low literacy attainment in English language among Malaysian learners (Musa et al., 2012).

(Chandrasegaran, 1993) and (Hashemnezhad \& Hashemnezhad, 2012) pointed 
out that it is important to be able to write coherent, well organized expository essays because academic assessment is almost entirely based on these written products. Thus, students who lack of effective written communication skills are disadvantaged as they will be unable to produce clear and convincing arguments to demonstrate in their writing products.

Although the teaching of writing has undergone major changes, Malaysian ESL students still seem to be receiving inadequate or outmoded writing instruction (Chow, 2007). It asserts that the usual explanations for poor student performance, such as illogical thinking, lack of academic commitment, and poor mastery of grammar (Chandrasegaran, 1993). Based on (Chandrasegaran, 1993), students are able to write committedly is because the content that they acquired is adequate. This could affect students' belief about their ability to answer a writing task. It could also be observed that students spend longer time choosing the type of essay than to answer the question.

\section{Methodology}

This study employed a survey research design. Questionnaire with 25 items was used to collect the data. The questions were divided according to the type of essays: Factual Essay, Narrative Essay, Descriptive Essay, Reflective Essay and Argumentative Essay. Each essay consisted of five questions. To guide the students, an example for each essay question was provided. This section of the questionnaire was designed using the data measurement scale of interval data type. It was designed using the Likert scale method which consisted of five levels: Strongly Disagree, Disagree, Not Sure, Agree and Strongly Agree. The respondents for this research were selected among upper secondary Malaysian school students. A total of 70 respondents were asked to respond to the survey.

\section{Results and Discussion}

The findings are presented in following sections. Each section discusses students' answer based on the different types of essay which are factual essay, narrative essay, descriptive essay, reflective essay and argumentative essay.

\subsection{Reasons for Selecting Essay: Factual Essay}

Figure 1 presents the factors that influencing students for choosing factual essay. Out of 70 respondents, $34.29 \%$ (24) responded that easy to find points as their main factor for selecting factual essay during the examination. The second most influenced factor is confident in completing the essay within the time allocated for them with $25.71 \%$ (18). It is then followed by confident with their writing skills with $21.43 \%$ (15), while the least selected reason is confident with their vocabulary skills with $14.29 \%$ (10).

\subsection{Reasons for Selecting Essay: Narrative Essay}

The following figure (Figure 2) presents factors that influencing students for choosing narrative essay. 


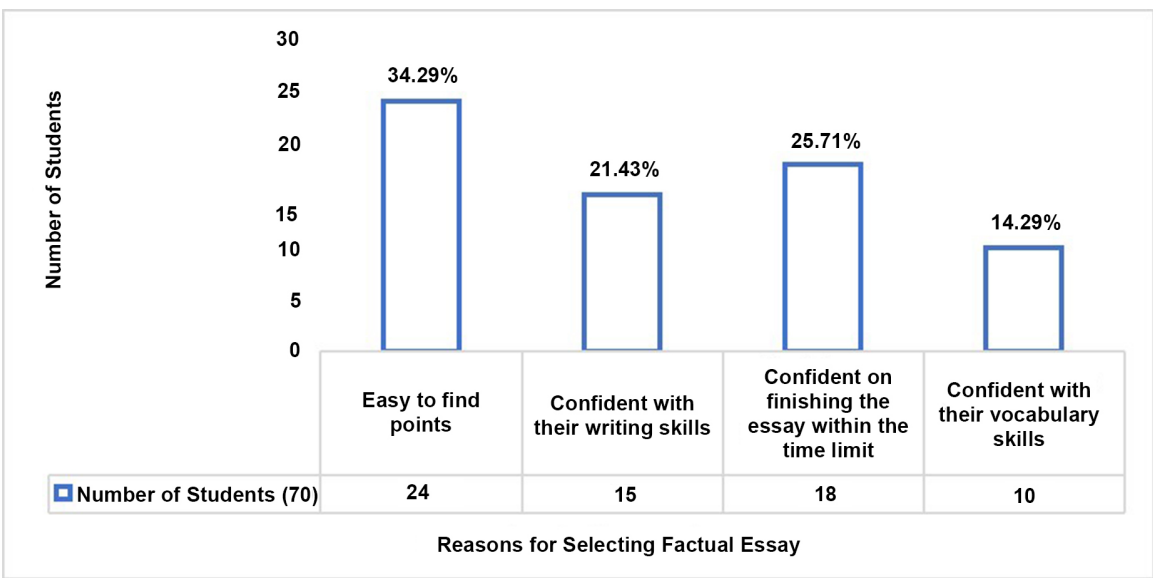

Figure 1. Factors influencing students' selection for factual essay.

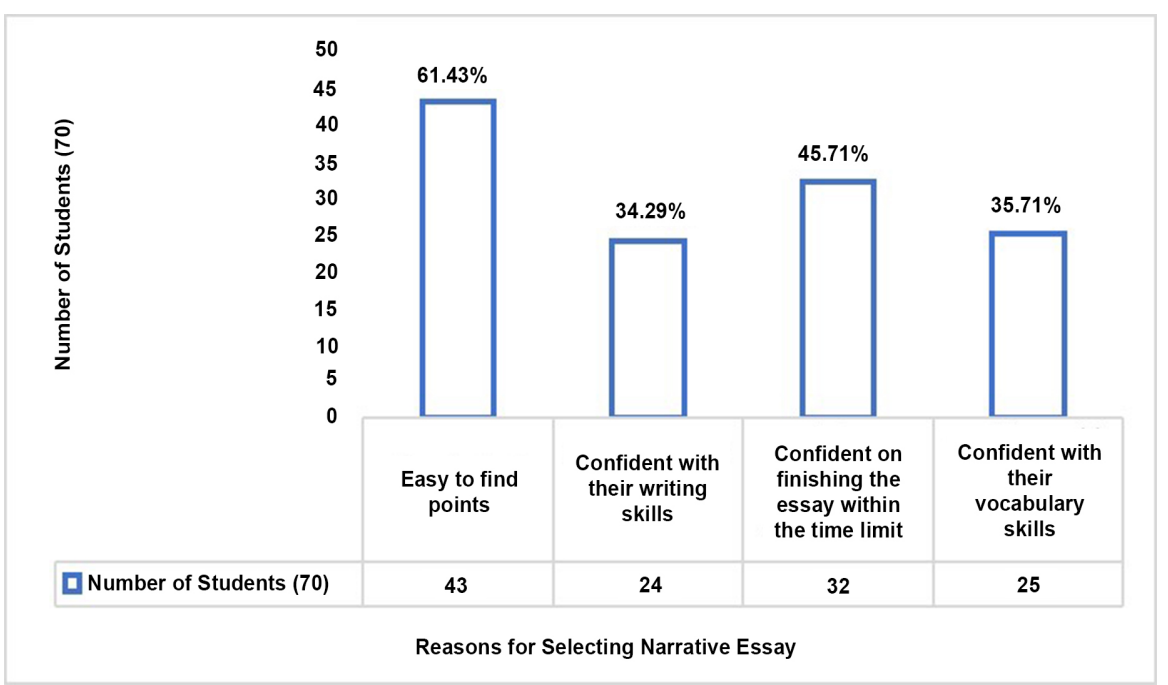

Figure 2. Factors influencing students' selection for narrative essay.

Out of 70 respondents, $61.43 \%$ (43) chose easy to find points as their main factor that influenced them in selecting narrative essay during the examination. The second highest factor is their confident on completing the essay within the time allocated with $45.71 \%$ (32). It is then followed by confident with their vocabulary skills with $35.71 \%$ (25), while the least selected factor is confident with their writing skills with $34.29 \%$ (24).

\subsection{Reasons for Selecting Essay: Reflective Essay}

Figure 3 presents the factors that influencing students for choosing reflective essay.

For the reflective essay, there were two most influential factors which are easy to find points and confident in their writing skills with $32.86 \%$ (23) out of 70 respondents respectively. It is followed by students' confident in completing the essay within the time allocated with $31.43 \%$ (22). The lowest factor is confident with vocabulary skills with $25.71 \%$ (18). 


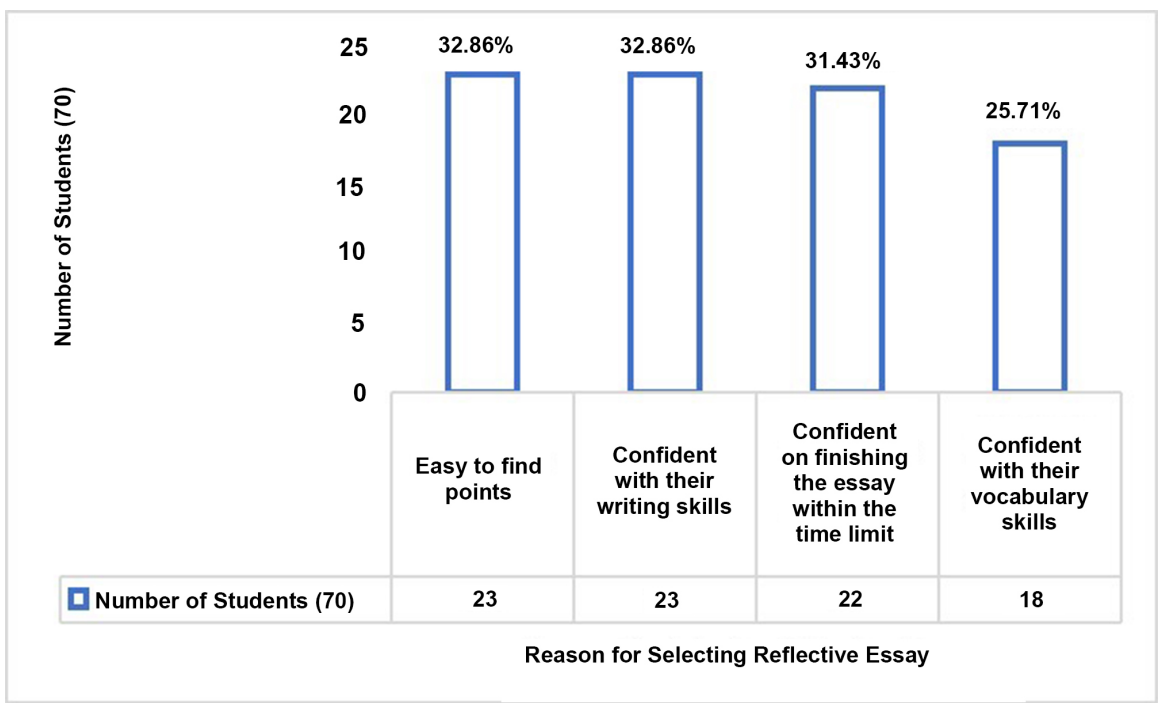

Figure 3. Factors influencing students' selection for reflective essay.

\subsection{Reasons for Selecting Essay: Descriptive Essay}

Figure 4 presents the factors that influencing students for choosing descriptive essay.

Out of 70 respondents, $57.14 \%$ (40) mentioned that the factor that influenced them is easy to find points as their reasons for selecting descriptive essay during the examination. The second highest factor is confident in completing the essay within the time allocated with $45.71 \%$ (32). The lowest factor is confident with writing skills and confident with their vocabulary skills with $32.86 \%$ (23) respectively.

\subsection{Reasons for Selecting Essay: Argumentative Essay}

Figure 5 presents the factors that influencing students for choosing argumentative essay.

Based on Figure 5, out of 70 respondent, $37.14 \%$ (26) chose easy to find points as the main factor for selecting argumentative essay during the examination. The second highest factor is confident with their vocabulary skills with $34.29 \%$ (24). Confident with their writing skills is $32.86 \%$ (23), while the lowest factor is confident in completing the essay within the time allocated with $31.43 \%$ (22).

Overall, based on the findings, it could be seen that the main factor that influenced the upper secondary school students in Malaysia in the different type of essay during examination is because it is easy to find points. This result had proven that out of all the four factors, Malaysian upper secondary school students believed that content knowledge is the priority when selecting an essay question during examination. In their opinion, this might be the best method in ensuring them to score well in their essay question. This is supported by (Chandrasegaran, 1993) where students are found to be able to write committedly because the content that they acquired is adequate. 


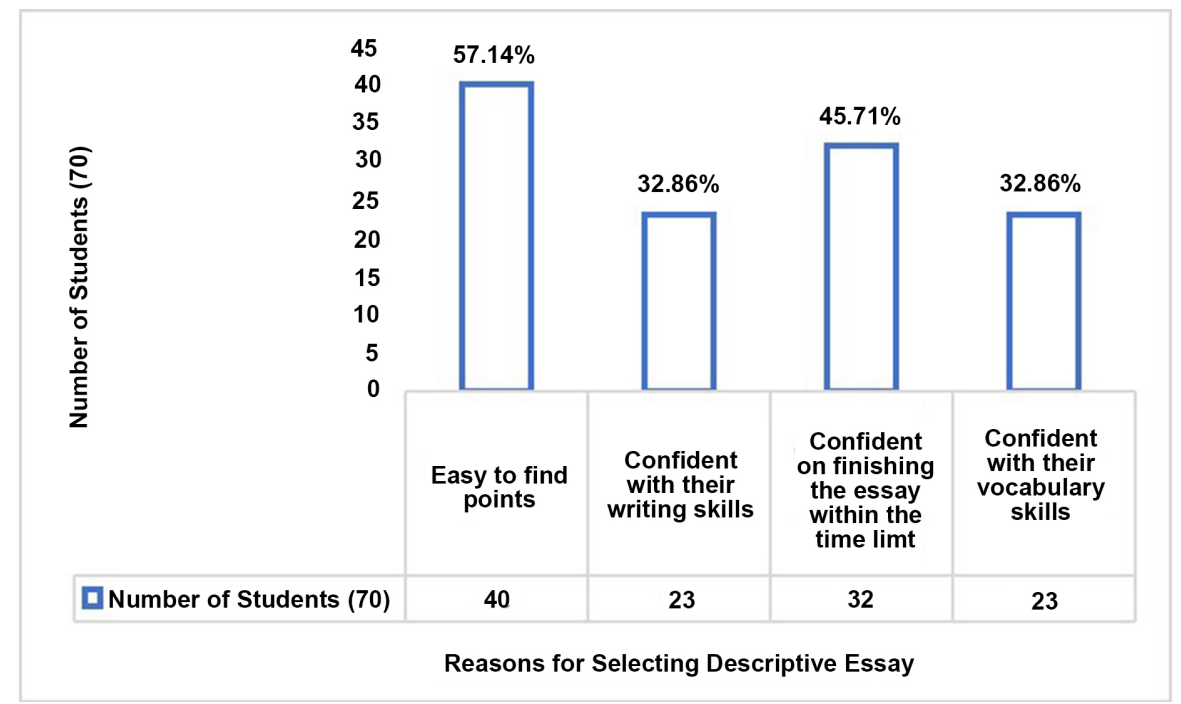

Figure 4. Factors influencing students' selection for descriptive essay.

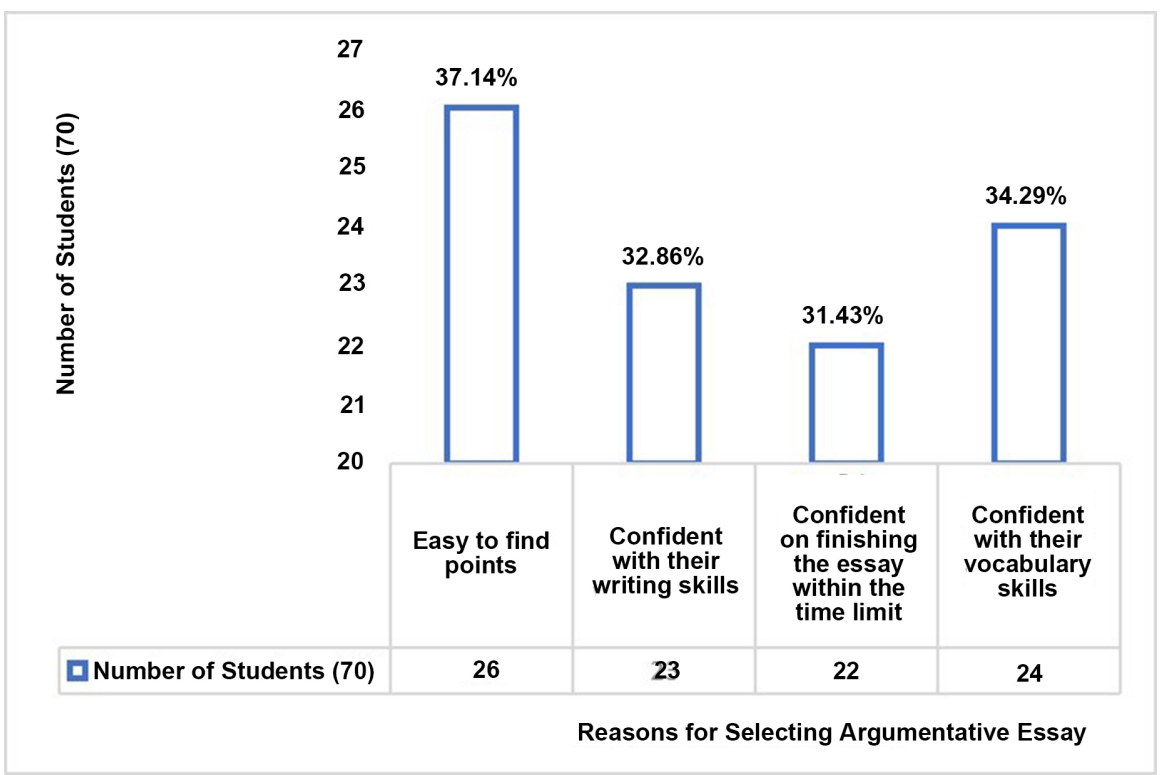

Figure 5. Factors influencing students' selection for argumentative essay.

\section{Conclusion}

Undeniably, narrative and descriptive essays require quite a high level of writing skills in which the students need to be able to be creative in expanding and generating their ideas. If they are not confident in that aspect, they will face the problem of not being able to finish their essay on time and producing a wellwritten essay. This summarise how exam-oriented the students are when selecting their essay question during examination. They have been drilled into their heads that the best way to score well in their essay examination is by coming up with many relevant points. And these points are usually memorized beforehand through the exercises teachers had given them during class. Despite their shortfall in that aspect, they seem to believe that vocabulary skills do not play a major 
role when selecting an essay during examination. As long as they know the points for the question and how to expand their ideas, they do not see the need to impress the examiner in the term of vocabulary skills. By determining the factor that influences students to choose type of essay question during examination, English teachers are able to design lesson plans for their writing classes that help and guide the students in strengthening their basic skills in writing their essay during examination. Future researches that cover the possible student-centred lesson plans for writing class can be outlined and benefited by both students and teachers.

\section{Conflicts of Interest}

The authors declare no conflicts of interest regarding the publication of this paper.

\section{References}

Al-Khasawneh, S. M. F. (2010). Writing for Academic Purposes: Problems Faced by Arab Postgraduate Students of the College of Business. ESP World, 9, 28.

http://www.esp-world.info

Chandrasegaran, A. (1993). Simplification in Student Writing.

Chow, T. V. F. (2007). The Effects of the Process-Genre Approach to Writing Instruction on the Expository Essays of ESL Students in a Malaysian Secondary School. PhD Diss., Penang: Universiti Sains Malaysia.

Ghabool, N., \& Kashef, S. H. (2012). Investigating Malaysian ESL Students' Writing Problems on Conventions, Punctuation, and Language Use at Secondary School Level. Journal of Studies in Education, 2, 130-143. https://doi.org/10.5296/jse.v2i3.1892

Hashemnezhad, H., \& Hashemnezhad, N. (2012). A Comparative Study of Product, Process, and Post-Process Approaches in Iranian EFL Students' Writing Skill. Journal of Language Teaching and Research, 3, 722. https://doi.org/10.4304/jltr.3.4.722-729

Musa, C. N., Lie, Y. K., \& Azman, H. (2012). Exploring English Language Learning and Teaching in Malaysia. Journal of Language Studies, 12, 35-51.

Tan, E. K., \& Miller, J. (2008). Writing in English in Malaysian High Schools: The Discourse of Examinations. England: Routledge.

Zamel, V. (1983). The Composing Process of Advanced ESL Students: Six Case Studies. TESOL Quarterly, 17, 165-187. https://doi.org/10.2307/3586647 